\title{
The Neuroscientist
}

http://nro.sagepub.com/

\section{PET Studies of Cerebral Levodopa Metabolism: A Review of Clinical Findings and Modeling Approaches \\ Yoshitaka Kumakura and Paul Cumming \\ Neuroscientist 2009 15: 635 originally published online 29 September 2009 \\ DOI: $10.1177 / 1073858409338217$}

The online version of this article can be found at:

http://nro.sagepub.com/content/15/6/635

Additional services and information for The Neuroscientist can be found at:

Email Alerts: http://nro.sagepub.com/cgi/alerts

Subscriptions: http://nro.sagepub.com/subscriptions

Reprints: http://www.sagepub.com/journalsReprints.nav

Permissions: http://www.sagepub.com/journalsPermissions.nav

Citations: http://nro.sagepub.com/content/15/6/635.refs.html

>> Version of Record - Dec 10, 2009

OnlineFirst Version of Record - Sep 29, 2009

What is This? 


\author{
Yoshitaka Kumakura and Paul Cumming
}

$\left[{ }^{18}\right.$ F]Fluoro-3,4-dihydroxyphenyl-L-alanine (FDOPA) was one of the first successful tracers for molecular imaging by positron emission tomography (PET), and has proven immensely valuable for studies of Parkinson's disease. Following intravenous FDOPA injection, the decarboxylated metabolite $\left[{ }^{18} \mathrm{~F}\right]$ fluorodopamine is formed and trapped within terminals of the nigrostriatal dopamine neurons; reduction in the simple ratio between striatum and cerebellum is indicative of nigrostriatal degeneration. However, the kinetic analysis of dynamic FDOPA-PET recordings is formidably complex due to the entry into brain of the plasma metabolite O-methyl-FDOPA and due to the eventual washout of decarboxylated metabolites. Linear graphical analysis relative to a reference tissue input function is popular and convenient for routine clinical studies in which serial arterial blood samples are unavailable. This simplified approach has facilitated longitudinal studies in large patient cohorts. Linear graphical analysis relative to the metabolite-corrected arterial FDOPA input yields a more physiological index of FDOPA utilization, the net blood-brain clearance. Using a constrained compartmental model, FDOPA-PET recordings can be used to calculate the relative activity of the enzyme DOPA decarboxylase in living brain. We have extended this approach so as to obtain an index of steady-state trapping of $\left[{ }^{18} \mathrm{~F}\right]$ fluorodopamine in synaptic vesicles. Although simple methods of image analysis are sufficient for the purposes of routine clinical studies, the more complex approaches have revealed hidden aspects of brain dopamine in personality, healthy aging, and in the pathophysiologies of Parkinson's disease and schizophrenia.

Keywords: FDOPA; fluorodopa; PET; kinetic modeling; steady state; Parkinson's disease; schizophrenia; aging
$\mathrm{T}$ The synthetic amino acid $\left[{ }^{18} \mathrm{~F}\right]$ fluoro-3,4-dihydroxyphenyl-L-alanine (FDOPA) was one of the first tracers available for molecular brain imaging by positron emission tomography (PET). During the past 25 years, FDOPA, along with $\left[{ }^{11} \mathrm{C}\right]$ DOPA and some other radioactive substrates for aromatic amino acid decarboxylase (AAADC), has emerged as an invaluable agent for the investigation of the functional state of dopamine innervations in living brain. Dynamic FDOPA-PET recordings reveal a time-dependent distribution of radioactivity in the brain in the hours after intravenous injection of the tracer. Whereas the initial influx of FDOPA to brain is spatially homogeneous, the radioactivity concentration within the healthy striatum soon surpasses that seen in other brain regions. This is

From the Department of Nuclear Medicine, Graduate School of Medicine, University of Tokyo, and Research Center for Advanced Science and Technology, the University of Tokyo, Tokyo, Japan (YK); and Department of Nuclear Medicine, Ludwig-Maximilians University, Munich, Germany (PC).

Address correspondence to: Yoshitaka Kumakura, MD, PhD, Research Center for Advanced Science \& Technology, The University of Tokyo, 4-6-1 \#34 Komaba, Meguro-ku, Tokyo, 153-8904, Japan; e-mail: yoshi. kumakura@gmail.com. certainly due to the formation of the AAADC product $\left[{ }^{18} \mathrm{~F}\right]$ fluorodopamine and the trapping of this product in synaptic vesicles of nigrostriatal fibers. Thus, specific radiolabeling of dopamine neurons can be visualized at approximately 1 hour after FDOPA injection, when the maximum contrast between striatum and nonbinding reference regions occurs (Garnett and others 1983).

The ratio between striatum and cerebellum radioactivity in an FDOPA study is a robust indicator of the integrity of the nigrostriatal dopamine pathway. However, the physiological interpretation of FDOPA-PET requires explicit pharmacokinetic models. There are a number of competing approaches for quantifying FDOPA-PET; model selection always entails a trade-off between real physiological complexity, and the simplicity and robustness of the method. Diverse approaches to FDOPA modeling have been tested and compared (Hoshi and others 1993), and the clinical findings have been reviewed (Cumming and Gjedde 1998). The present review summarizes the state of the art for analysis of FDOPA-PET, highlighting the advantages and disadvantages of the various methods. Some of the latest findings of preclinical and clinical PET studies with FDOPA are presented, with an emphasis on applications for psychiatry, neurology, and the study of human personality and cognition. 

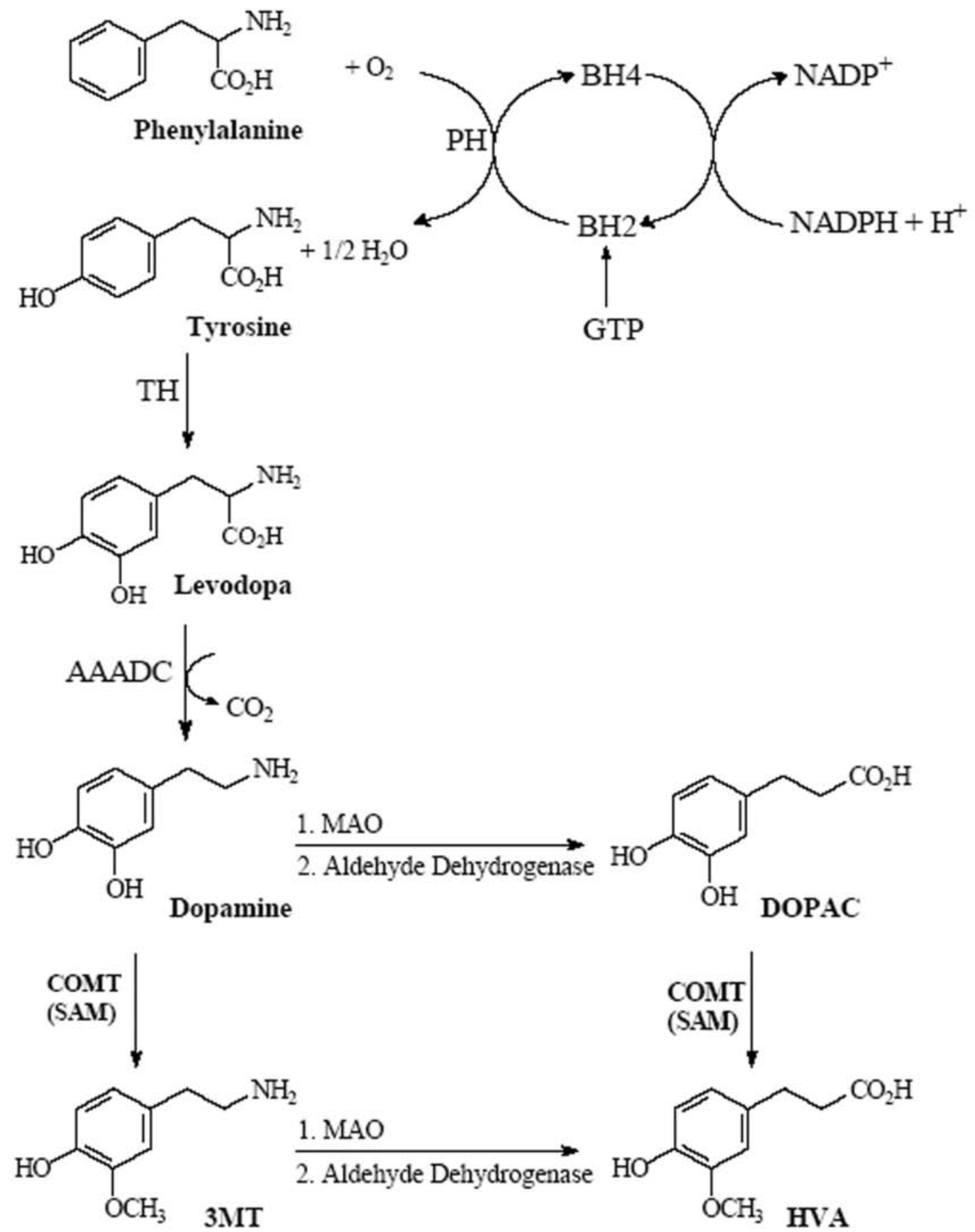

Figure 1. The pathway for the synthesis and catabolism of dopamine. Abbreviations: $\mathrm{PH}=$ phenylalanine hydroxylase; $\mathrm{BH} 2 / \mathrm{BH} 4=$ dihydo- and tetrahydrobiopterin; $\mathrm{TH}=$ tyrosine hydroxylase; $\mathrm{AAADC}=$ aromatic amino acid decarboxylase; $\mathrm{MAO}=$ monoamine oxidase; COMT = catechol-O-methyltransferase; SAM = S-adenosylmethionine; 3MT = 3-methoxyryramine; DOPAC = dihydroxyphenylacetic acid; HVA = homovanillic acid. Figure courtesy of Dr. Svend Jensen, Aarhus University.

\section{General Aspects of the Kinetic Analysis of FDOPA Metabolism}

PET recordings show the total radioactivity concentration in living tissue, irrespective of any biotransformation of the tracer. In the case of FDOPA-PET, the tracer enters into the pathway for dopamine synthesis (Fig. 1). Endogenous DOPA is normally synthesized in living brain by tyrosine hydroxylase. Consequently, FDOPAPET circumvents the classical rate-limiting step of 
catecholamine synthesis. Once entering striatum, FDOPA is decarboxylated by AAADC, yielding $\left[{ }^{18} \mathrm{~F}\right]$ fluorodopamine, which is retained for a time within dopamine vesicles, but is ultimately decomposed by the successive actions of monoamine oxidase (MAO) and catechol-O-methyltransferase (COMT). The resultant acidic metabolites, $\left[{ }^{18} \mathrm{~F}\right] \mathrm{DOPAC}$ and $\left[{ }^{18} \mathrm{~F}\right] \mathrm{HVA}$ (Cumming and others 1987), are free to diffuse out of brain.

Inasmuch as FDOPA is also a substrate for AAADC throughout the body, subjects for brain PET studies are generally pretreated with the peripherally acting AAADC inhibitor carbidopa. In this condition, plasma FDOPA is mainly metabolized by liver COMT. Within 30 minutes of FDOPA injection, the inert metabolite $O$-methyl-FDOPA (OMFD) is the major radioactive species in plasma of humans (Boyes and others 1986) and rats (Cumming and others 1987). The several approaches for the quantitation of cerebral FDOPA kinetics must somehow correct for the plasma-derived OMFD, which presents a homogeneous background radioactivity somewhat obscuring the signal related to $\left[{ }^{18} \mathrm{~F}\right]$ fluorodopamine synthesis.

\section{Other Substrates for PET Studies of AAADC}

Although FDOPA and DOPA are not distinguished by AAADC in vitro (Cumming and others 1988), FDOPA is a better substrate for COMT than is natural DOPA, such that large amounts of the plasma metabolite OMFD are formed in vivo (Cumming and others 1995a). The alternate tracer $\beta-\left[{ }^{11} \mathrm{C}\right] \mathrm{DOPA}$ is preferable for PET studies of AAADC metabolism, because it yields much less of the inert plasma metabolite (Torstenson and others 1999). Furthermore, the shorter half-life of $\left[{ }^{11} \mathrm{C}\right]$ $(20 \mathrm{~min})$ relative to $\left[{ }^{18} \mathrm{~F}\right](110 \mathrm{~min})$ might permit pharmacological challenge studies, in which a subject is scanned twice in succession on the same PET scanning day. Unfortunately, the complex radioenzymatic synthesis of $\beta-\left[{ }^{11} \mathrm{C}\right] \mathrm{DOPA}$ seems to have discouraged its widespread use. On the other hand, the $\left[{ }^{18} \mathrm{~F}\right]$-precursor or FDOPA itself can be shipped hundreds of kilometers from a cyclotron/radiochemistry facility.

The alternate AAADC substrate 6-[ $\left.{ }^{18} \mathrm{~F}\right]-\mathrm{L}$-metatyrosine (FMT) is not a substrate for COMT, and so does not yield a kinetically troublesome brain-penetrating metabolite. FMT rapidly enters brain and gives rise to a more intense labeling of striatum than is typical of FDOPA (Brown and others 1999). Influx plots of FMT or FDOPA were equally sensitive to the nigrostriatal degeneration in monkeys with MPTP-induced parkinsonism, although only FDOPA revealed clear evidence of the late washout phase related to breakdown of dopamine (Doudet and others 1999). Perplexingly, the decarboxylated product of FMT, 6- $\left[{ }^{18} \mathrm{~F}\right]$-meta-tyramine, is not sequestered in synaptic vesicles (Endres and others 1997), but is instead rapidly metabolized by MAO, yielding the acidic metabolite $\left[{ }^{18} \mathrm{~F}\right]$ hydroxyphenylacetic acid (Jordan and others 1998). In general, acidic metabolites should diffuse from brain, so it is unclear how the specific FMT signal is retained so effectively within living striatum.

\section{FDOPA: The "Worst Case" Scenario}

FDOPA kinetic modeling is based upon the earlier experience with FDG, the tracer for PET studies of glucose consumption (Phelps and others 1979). Whereas the model for analysis FDG-PET safely assumes irreversible trapping of the tracer in brain, the explicit FDOPA model is considerably more complex. Indeed, the kinetic modeling of FDOPA is a "worst case" scenario, due to the entry of the plasma metabolite to brain, and due also to progressive violation of the assumption of irreversible trapping, that is, washout. In an explicit FDOPA model, each biochemical or physiological process is expressed as a kinetic term, the definitions and abbreviations of which are listed in Table 1. In practice, it is necessary to reduce the complexity of the model, as illustrated in Figure 2A, which is essentially a simplification of the more detailed models presented earlier (Huang and others 1991; Cumming and Gjedde 1998). Due to the nature of the dopamine pathway, an FDOPAPET recording lasting several hours reveals three distinct phases: 1) the initial tracer uptake across the blood-brain barrier, 2) the formation and trapping of $\left[{ }^{18} \mathrm{~F}\right]$ fluorodopamine in dopamine vesicles, and 3$)$ the late phase of washout of acidic metabolites.

Complete FDOPA kinetic modeling requires serial arterial blood samples, obtained from a catheter placed in a radial artery, to measure the total radioactivity concentration as a function of time after injection. This proportions of untransformed FDOPA and OMFD in plasma change continuously and must be separated. In the early days, the FDOPA and OMFD fractions were separated from blood plasma using powdered alumina (Boyes and others 1986), but this solid-phase method has been largely supplanted by HPLC (Cumming and others 1993). The end result is a pair of arterial inputs, one for the declining amounts of untransformed FDOPA and one for the increasing amounts of OMFD.

\section{Gjedde-Patlak Linear Graphic Analysis Applied to FDOPA}

When a "pure" FDOPA arterial input is available, FDOPA uptake in brain can be analyzed by a linear graphical analysis, derived from the method for calculating net flux of FDG to brain (Gjedde 1982; Patlak and others 1983). The troublesome plasma metabolite OMFD enters readily into the brain and soon becomes the predominant radioactive compound in most regions 
Table 1. Definitions of Abbreviations and Kinetic Terms Used in the Text

\begin{tabular}{|c|c|c|}
\hline Term & Units & Definition \\
\hline FDOPA & & 6-[ $\left[{ }^{18} \mathrm{~F}\right]$ Fluoro-3,4,-dihydroxyphenyl-L-alanine \\
\hline OMFD & & O-Methyl-FDOPA \\
\hline$K_{1}$ & $\mathrm{~mL} \mathrm{~g}^{-1} \min ^{-1}$ & $\begin{array}{l}\text { Unidirectional blood-brain clearance of a tracer across } \\
\text { blood-brain barrier, } K_{1}^{D} \text { for FDOPA and } K_{1}^{M} \text { for OMFD }\end{array}$ \\
\hline$k_{2}$ & $\min ^{-1}$ & $\begin{array}{l}\text { Fractional rate constant for the diffusion of a tracer } \\
\text { from brain, } k_{2}^{D} \text { for FDOPA, and } k_{2}^{M} \text { for OMFD }\end{array}$ \\
\hline$V_{e}$ & $\mathrm{~mL} \mathrm{~g}^{-1}$ & $\begin{array}{l}\text { The equilibrium distribution volume of a tracer in a nontrapping } \\
\text { region }\left(K_{1}^{D} / k_{2}^{D} \text { for FDOPA) }\right.\end{array}$ \\
\hline$k_{3}{ }^{D}$ & $\min ^{-1}$ & $\begin{array}{l}\text { The relative activity of DOPA decarboxylase with respect to FDOPA, } \\
\text { calculated assuming irreversible trapping of decarboxylated metabolites } \\
\text { in brain, uncorrected for the loss, i.e., uncorrected for the real loss of } \\
\text { these metabolites }\end{array}$ \\
\hline$k_{3}$ & $\min ^{-1}$ & $\begin{array}{l}\text { The relative activity of DOPA decarboxylase with respect } \\
\text { to FDOPA, inherently corrected for the loss of decarboxylated } \\
\text { metabolites from brain. (Identical to } k_{3}^{D^{*}} \text { in Cumming and others 2001) }\end{array}$ \\
\hline$k_{3}^{S}\left(\right.$ or $\left.K^{o c c}\right)$ & $\min ^{-1}$ & $\begin{array}{l}\text { The utilization rate constant of FDOPA calculated by graphical } \\
\text { analysis using an (occipital cortex) reference tissue input }\end{array}$ \\
\hline$K_{i n}^{a p p}$ & $\mathrm{~mL} \mathrm{~g}^{-1} \min ^{-1}$ & $\begin{array}{l}\text { The net unidirectional blood-brain clearance of FDOPA } \\
\text { in a region of interest calculated by graphical analysis, with subtraction } \\
\text { of the total radioactivity measured in a non-trapping region, and assuming } \\
\text { no elimination of decarboxylated metabolites. Identical to } K_{1}{ }^{D} /\left(k_{2}{ }^{D}+k_{3}{ }^{D}\right) \text {. }\end{array}$ \\
\hline$K$ & $\mathrm{~mL} \mathrm{~g}^{-1} \min ^{-1}$ & $\begin{array}{l}\text { The intrinsic blood-brain clearance of a tracer defined kinetically } \\
\text { in terms of } K_{1}, k_{2} \text { and } k_{3} \text {. (Kumakura and others 2005) } \\
\text { Identical to } K_{1}^{D} /\left(k_{2}{ }^{D}+k_{3}\right) \text {. }\end{array}$ \\
\hline$k_{\text {loss }}$ & $\min ^{-1}$ & $\begin{array}{l}\text { The rate constant for the elimination of decarboxylated FDOPA metabolites } \\
\text { from brain (See: Holden and others 1997) }\end{array}$ \\
\hline$E D V$ & $\mathrm{~mL} \mathrm{g^{-1 }}$ & $\begin{array}{l}\text { The ratio } K / k_{\text {loss }} \text {, an index of the steady-state storage of the metabolite } \\
\text { compartment in brain, following our previous definition of } E D V^{2} \text { (Kumakura } \\
\left.\text { and others } 2005,2006 \text {; cf. } E D V^{I}\right) \text {. }\end{array}$ \\
\hline$V_{0}$ & $\mathrm{~mL} \mathrm{~g} \mathrm{~g}^{-1}$ & Effective plasma volume \\
\hline$V_{f}$ & $\mathrm{~mL} \mathrm{\textrm {g } ^ { - 1 }}$ & Distribution volume of precursor pool \\
\hline$V_{d}$ & $\mathrm{~mL} \mathrm{~g}^{-1}$ & $\begin{array}{l}\text { Total distribution volume in brain tissue }\left(=E D V+V_{f}+V_{0}\right) \text {, } \\
\text { an index of the steady-state storage in brain }\end{array}$ \\
\hline
\end{tabular}

of rat brain (Cumming and others 1987) and primate brain (Firnau and others 1987). To isolate the process of FDOPA trapping in brain, it is first necessary to subtract by some means the brain radioactivity due to OMFD, which is generally assumed to be the sole labeled metabolite in reference regions, that is, the cerebellum or occipital cortex (Fig. 2B). Subtraction of the entire radioactivity in the reference region has been a convenient approximation for calculation of FDOPA influx in the presence of interference from OMFD (Martin and others 1989). Following this crude subtraction, the linear regression slope of the plot of FDOPA distribution volume $\left(\mathrm{C}_{\mathrm{t}}(\mathrm{t}) / \mathrm{C}_{\mathrm{p}}(\mathrm{t})\right)$ versus the normalized arterial FDOPA input $\left(\operatorname{IntC}_{p}(t) / C_{p}(t)\right)$ is defined as the net blood-brain FDOPA clearance $\left(K_{i n}{ }^{a p p}\right.$; $\mathrm{mL} \mathrm{g}^{-1} \mathrm{~min}^{-1}$ ), an index of the capacity for dopamine synthesis in striatum.

Some representative results obtained using the linear graphic analysis in monkey and human are presented in Table 2. The magnitude of $K_{i n}{ }^{a p p}$ is a sensitive indicator of nigrostriatal degeneration, although its physiological interpretation is subject to several caveats. In particular, $K_{\text {in }}{ }^{a p p}$ (Fig. 2) is a macroparameter comprised of the FDOPA diffusion across the blood-brain barrier and the rate of decarboxylation by brain AAADC. Inasmuch as the initial transfer to brain is sensitive to competition from other substrates for the common carrier of large neutral amino acids, FDOPA-PET subjects should be scanned in a fasting condition. The magnitude of $K_{\text {in }}{ }^{a p p}$ reveals the maximal capacity for synthesizing dopamine from DOPA arriving in blood, but does not indicate the real rate of dopamine synthesis from DOPA formed in situ.

When, as is often the case, it is impractical to measure the arterial FDOPA input, an alternate index of FDOPA utilization can be calculated by linear graphic analysis relative to a reference tissue, assumed to be devoid of AAADC activity. The time activity curve (TAC) measured in a reference region (Fig. 3B) serves as a surrogate for the missing arterial FDOPA input for 


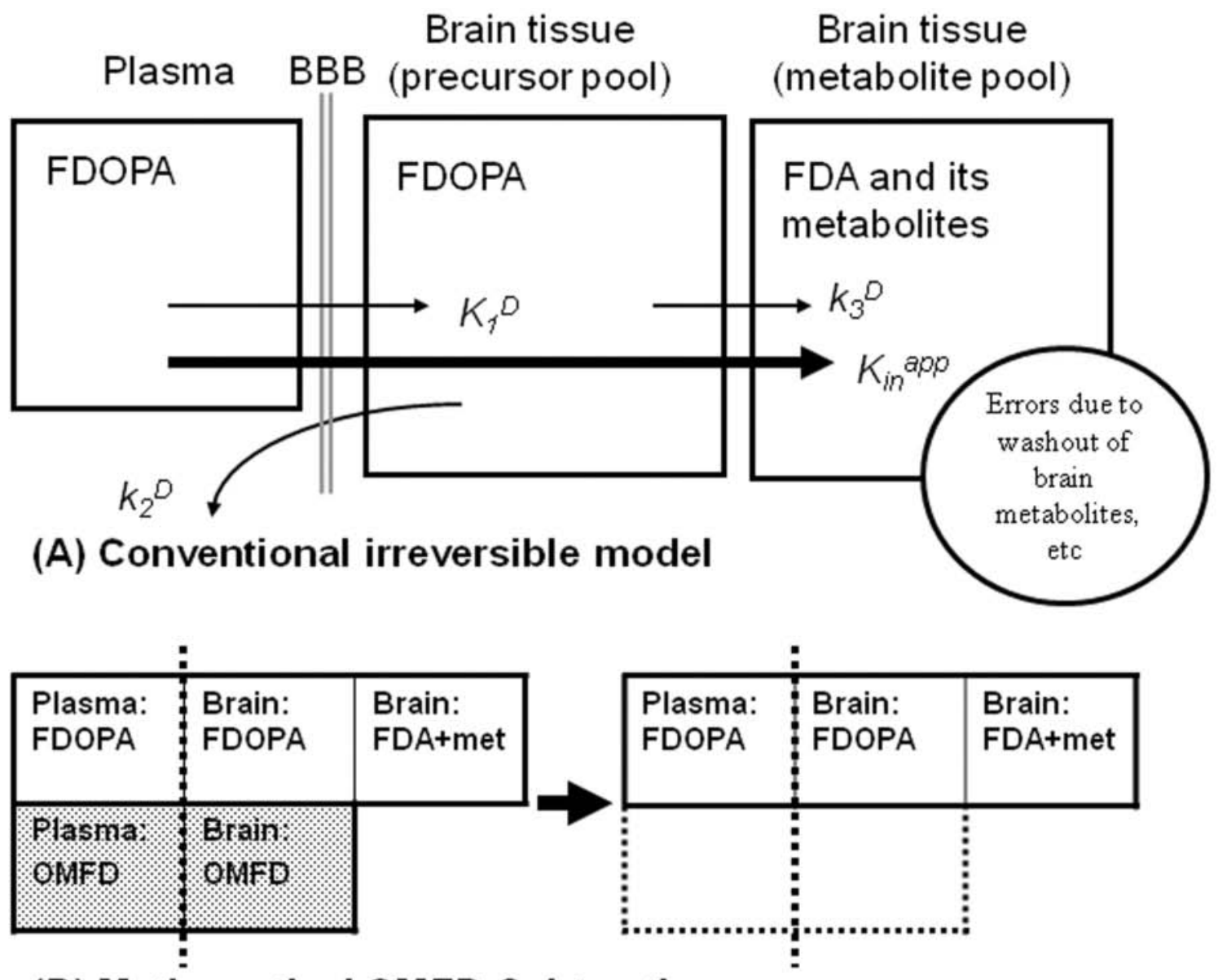

(B) Mathematical OMFD Subtraction

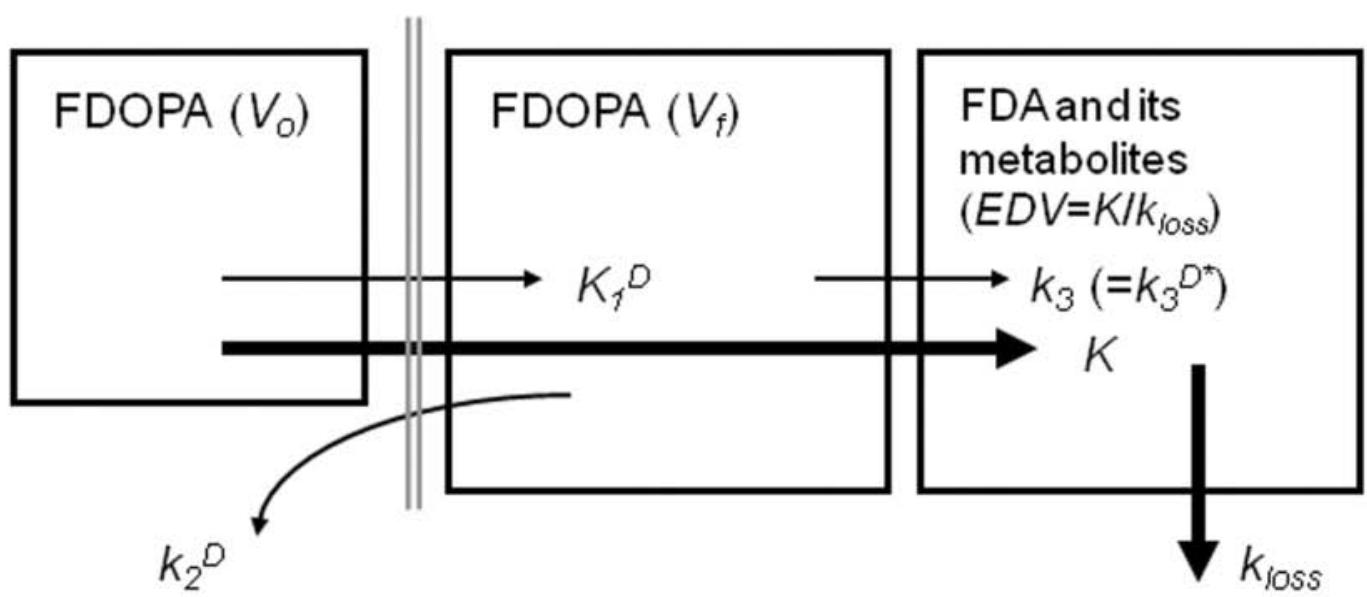

(C) Reversible "inlet \& outlet" model

Figure 2. A schema describing the kinetic models of 6- $\left[{ }^{18} \mathrm{~F}\right]$ fluoro-L-dopa (FDOPA). $A$, The distribution of FDOPA across the blood-brain barrier is mediated by the unidirectional clearance $\left(K_{1}^{D} ; \mathrm{mL} \mathrm{g}^{-1} \mathrm{~min}^{-1}\right)$, and the facilitated diffusion back to circulation $\left(k_{2}{ }^{D} ; \mathrm{min}^{-1}\right)$. FDOPA residing in the precursor pool is decarboxylated by aromatic amino acid decarboxylase (AAADC; $k_{3}^{D}$; min $^{-1}$ ) and is assumed to be irreversibly trapped. The net influx $\left(K_{i n}^{a p p} ; \mathrm{mL} \mathrm{g}^{-1} \mathrm{~min}^{-1}\right)$ is a macroparameter comprising the preceding processes. For the sake of clarity, 3-Omethyl- $\left[{ }^{18} \mathrm{~F}\right] \mathrm{FDOPA}(\mathrm{OMFD})$ is not included in this schema, but is indicated in $B$. The contribution of OMFD to brain radioactivity must be removed by subtraction. $C$, The distribution volume of the tracer in a brain region is distributed into three compartments: intravascular space $\left(V_{o}, \mathrm{~mL} \mathrm{~g}^{-1}\right)$, extravascular tissue (precursor pool, $V_{f}, \mathrm{~mL} \mathrm{~g}^{-1}$ ), and metabolite compartment (trapped tracer, $E D V, \mathrm{~mL} \mathrm{~g}^{-1}$ ). Here, the AAADC activity is designated $k_{3}{ }^{*}$, to indicate that it is corrected for loss of metabolites, as is the intrinsic blood-brain clearance of FDOPA $\left(K, \mathrm{~mL} \mathrm{~g}^{-1} \mathrm{~min}^{-1}\right)$. The AAADC product $\left[{ }^{18} \mathrm{~F}\right]$ fluorodopamine formed in brain, together with its acidic metabolites, is assumed to diffuse from the brain as a single compartment $\left(k_{\text {loss }}, \mathrm{min}^{-1}\right)$. 
Table 2. Results of Some Quantitative Studies of FDOPA Metabolism in Striatum of Monkey and Human

Monkey

(Cumming and others 2001)

Caudate

$\begin{aligned} 0.0127 & \pm 0.0045 \\ 0.0043 & \pm 0.0034 \\ 0.033 & \pm 0.010 \\ 0.010 & \pm 0.007 \\ 0.0022 & \pm 0.0008 \\ 0.0056 & \pm 0.0034\end{aligned}$

Putamen

Normal $(\mathrm{n}=6)$
MPTP $(\mathrm{n}=6)$
Normal
MPTP
Normal
MPTP

$0.0123 \pm 0.0043$

$0.0041 \pm 0.0027$

$0.035 \pm 0.006$

$0.009 \pm 0.005$

$0.0016 \pm 0.0003$

$0.0054 \pm 0.0030$
Healthy young $(\mathbf{n}=7)$

Healthy aged $(n=8)$

Healthy young

Healthy aged

Healthy young

Healthy aged

Healthy young

Healthy aged
$0.0082 \pm 0.0021$
$0.0082 \pm 0.0017$
$0.0135 \pm 0.0038$
$0.0132 \pm 0.0025$
$0.0013 \pm 0.0008$
$0.0035 \pm 0.0017$
$13.8 \pm 7.2$
$4.8 \pm 2.8$

(Kumakura and others 2006)

$K_{\text {in }}{ }^{a p p}\left(\mathrm{~mL} \mathrm{~g}^{-1} \mathrm{~min}^{-1}\right)$
$k_{\text {loss }}\left(\mathrm{min}^{-1}\right)$
$\operatorname{EDV}\left(\mathrm{mL} \mathrm{g}^{-1}\right)$

\author{
Healthy aged $(n=6)$ \\ Parkinson's disease $(\mathbf{n}=8)$ \\ Healthy aged \\ Parkinson's disease \\ Healthy aged \\ Parkinson's disease
}

$\begin{aligned} 0.0067 & \pm 0.0017 \\ 0.0040 & \pm 0.0031 \\ 0.0052 & \pm 0.0018 \\ 0.0090 & \pm 0.0043 \\ 2.6 & \pm 1.3 \\ 1.6 & \pm 1.0\end{aligned}$

$0.0111 \pm 0.0012$

$0.0062 \pm 0.0013$

$0.0046 \pm 0.0017$

$0.0114 \pm 0.0034$

$4.1 \pm 1.2$

$1.7 \pm 0.5$

(Kumakura and others 2007)

$K_{\text {in }}{ }^{a p p}\left(\mathrm{~mL} \mathrm{~g}^{-1} \mathrm{~min}^{-1}\right)$
$K\left(\mathrm{~mL} \mathrm{~g}^{-1} \mathrm{~min}^{-1}\right)$
$k_{\text {loss }}\left(\mathrm{min}^{-1}\right)$
$V_{d}\left(\mathrm{~mL} \mathrm{~g}^{-1}\right)$

$K_{\text {in }}^{\text {app }}\left(\mathrm{mL} \mathrm{g}^{-1} \mathrm{~min}^{-1}\right)$

$V_{d}\left(\operatorname{mL} \mathrm{g}^{-1}\right)$

Healthy subjects $(\mathrm{n}=15)$
Schizophrenia $(\mathrm{n}=8)$
Healthy subjects
Schizophrenia
Healthy subjects
Schizophrenia
Healthy subjects
Schizophrenia

$\begin{aligned} 0.0081 & \pm 0.0018 \\ 0.0071 & \pm 0.0021 \\ 0.0144 & \pm 0.0033 \\ 0.0175 & \pm 0.0028 \\ 0.0041 & \pm 0.0012 \\ 0.0080 & \pm 0.0038 \\ 4.0 & \pm 1.8 \\ 2.5 & \pm 0.8\end{aligned}$

$$
\begin{aligned}
0.0117 & \pm 0.0019 \\
0.0126 & \pm 0.0019 \\
0.0181 & \pm 0.0036 \\
0.0237 & \pm 0.0042 \\
0.0037 & \pm 0.0015 \\
0.0063 & \pm 0.0029 \\
5.9 & \pm 2.7 \\
4.3 & \pm 1.1
\end{aligned}
$$

Mean results are presented from the non-steady-state analyses assuming irreversible trapping of decarboxylated metabolites $\left(k_{3}{ }^{S}=\right.$ the DOPA decarboxylase activity relative to a reference tissue input; $k_{3}{ }^{D}=$ the DOPA decarboxylase activity relative to the arterial input; $K_{\text {in }}{ }^{a p p}=$ the net blood-brain clearance) and for steady-state models $\left(K=\right.$ the net blood-brain clearance; $k_{\text {loss }}=$ the washout rate constant for $\left[{ }^{18} \mathrm{~F}\right]$ dopamine; $E D V=$ the steady-state storage effective for vesicular retention; $V_{d}=$ the total steady-state storage for 6-[ $\left.{ }^{18} \mathrm{~F}\right]$ fluoro-3,4,-dihydroxyphenyl-L-alanine [FDOPA] together with its decarboxylated metabolites). MPTP = neurotoxin-induced syndrome of acquired parkinsonism.

calculating the rate of FDOPA decarboxylation, here defined as $k_{3}{ }^{S}\left(\mathrm{~min}^{-1}\right)$ (Bruck and others 2006; Hoshi and others 1993; Ishiwata and others 2007). This approach has proven eminently useful for clinical studies of Parkinson's disease progression in large cohorts. Parametric maps (Fig. 4) show that the magnitude of $k_{3}{ }^{S}$ is reduced more in the putamen than in the caudate of patients with Parkinson's disease, consistent with post mortem findings.

There has been some confusion in terminology for the FDOPA reference tissue graphical analysis, which has been called $k_{3}^{s}, K_{i}$, $K^{o c c}$, or $K^{\text {ref }}$, all with units of $\min ^{-1}$ (Patlak and Blasberg 1985; Hoshi and others 1993). We prefer the term $k_{3}^{s}$, inasmuch as capital $K$ should properly be reserved for blood-brain clearances, which has units of $\mathrm{mL} \mathrm{g}^{-1} \mathrm{~min}^{-1}$ (Gjedde 1982; Patlak and others 1983). Despite different assumptions, the magnitude of $k_{3}^{s}$ actually correlates well with those of $K_{i n}{ }^{a p p}$ (see Fig. 4). Whatever it may be called, the slope of the reference tissue graphic analysis implicitly assumes that the fraction of FDOPA in the reference tissue remains constant over time (Hartvig and others 1991), whereas it is known that within 30 minutes after FDOPA injection, OMFD becomes the predominant 


\section{A Plasma TACs}

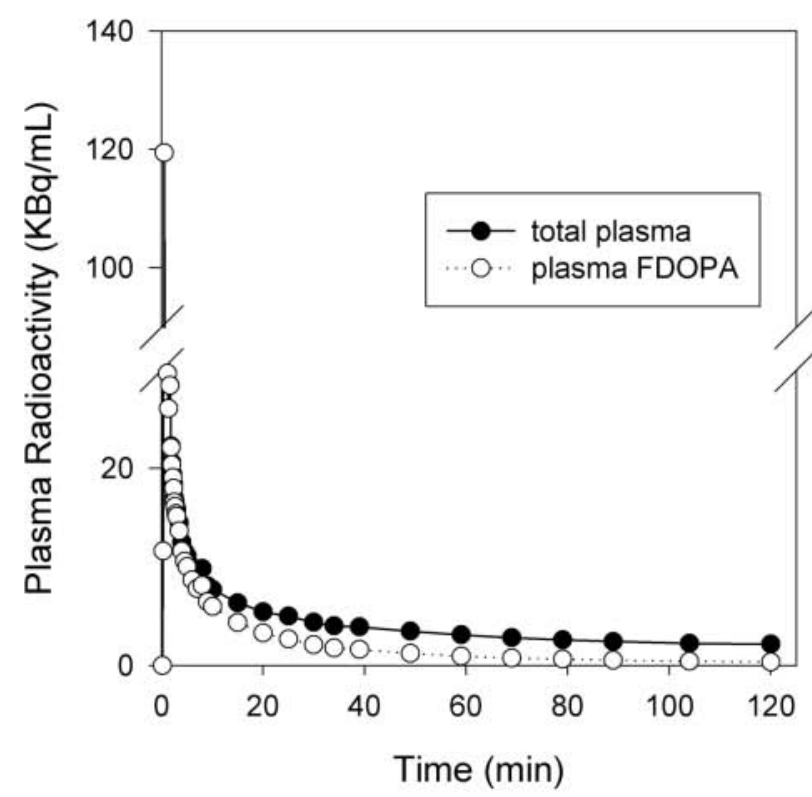

B Tissue TACs

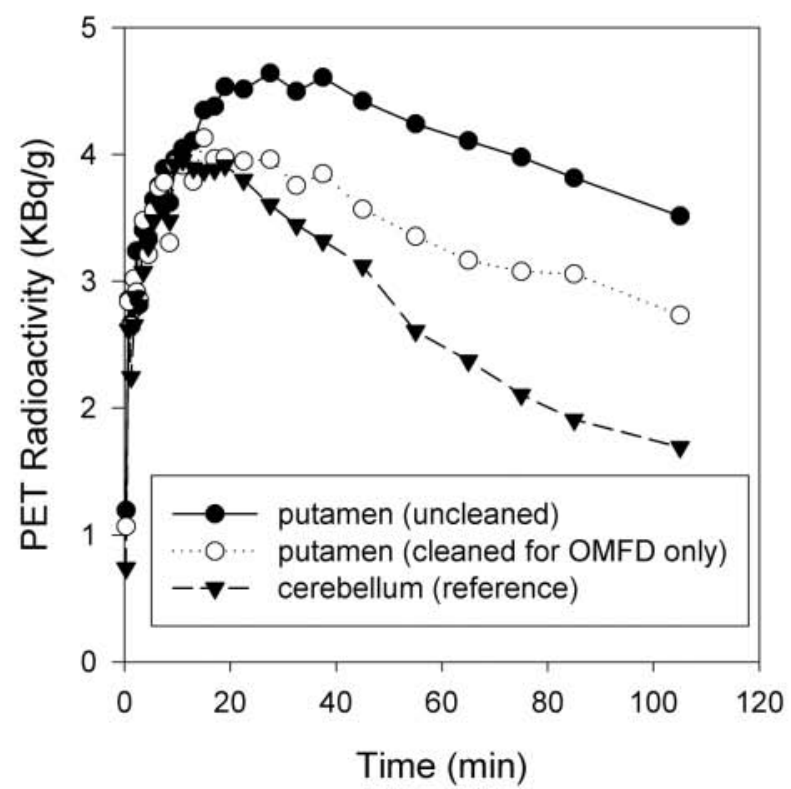

C Reference Tissue Patlak plot

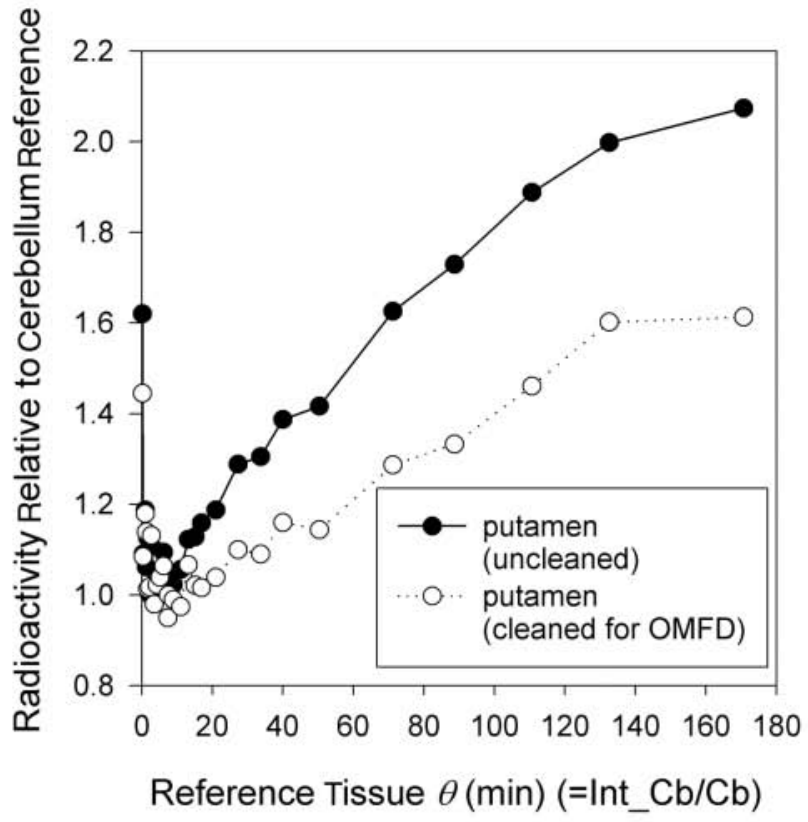

D Plasma Input Gjedde-Patlak plot

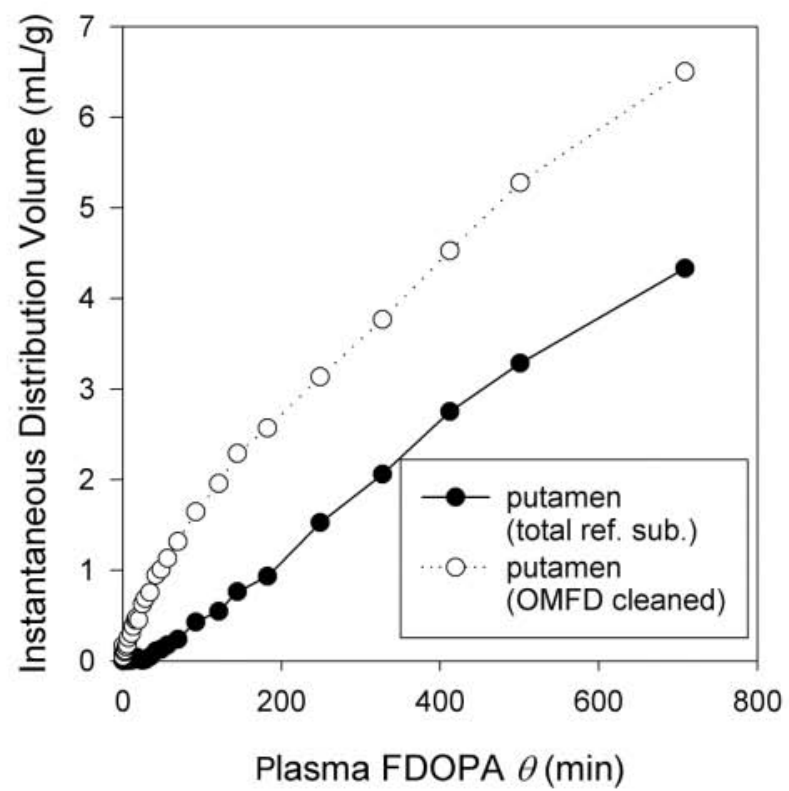

Figure 3. $6-\left[{ }^{18} \mathrm{~F}\right]$ Fluoro-L-dopa (FDOPA) kinetics in blood and brain. $A$, The total time radioactivity curve in arterial plasma $(\mathbf{0})$ and the concentration of FDOPA (O). B, Representative time-activity curves in cerebellum and putamen of a patient with mild Parkinson's disease, showing the effect of mathematical subtraction of the radioactivity due to 3-O-methyl-[ $\left.{ }^{18} \mathrm{~F}\right] \mathrm{FDOPA}$. $\mathrm{C}$, Reference tissue plots for the utilization of FDOPA in putamen. $D$, Linear graphical analysis of FDOPA influx in putamen, showing that conventional subtraction of cerebellum radioactivity $(\bullet)$ results in underestimation of the true net influx.

source of radioactivity in the reference tissue. Consequently, the magnitude of $k_{3}{ }^{s}$ must underestimate the true AAADC activity in striatum, because the reference tissue TAC progressively overestimates the real precursor concentration. Researchers who demand more strict physiological measures of AAADC must resort to compartmental modeling, rather than graphical analysis. 


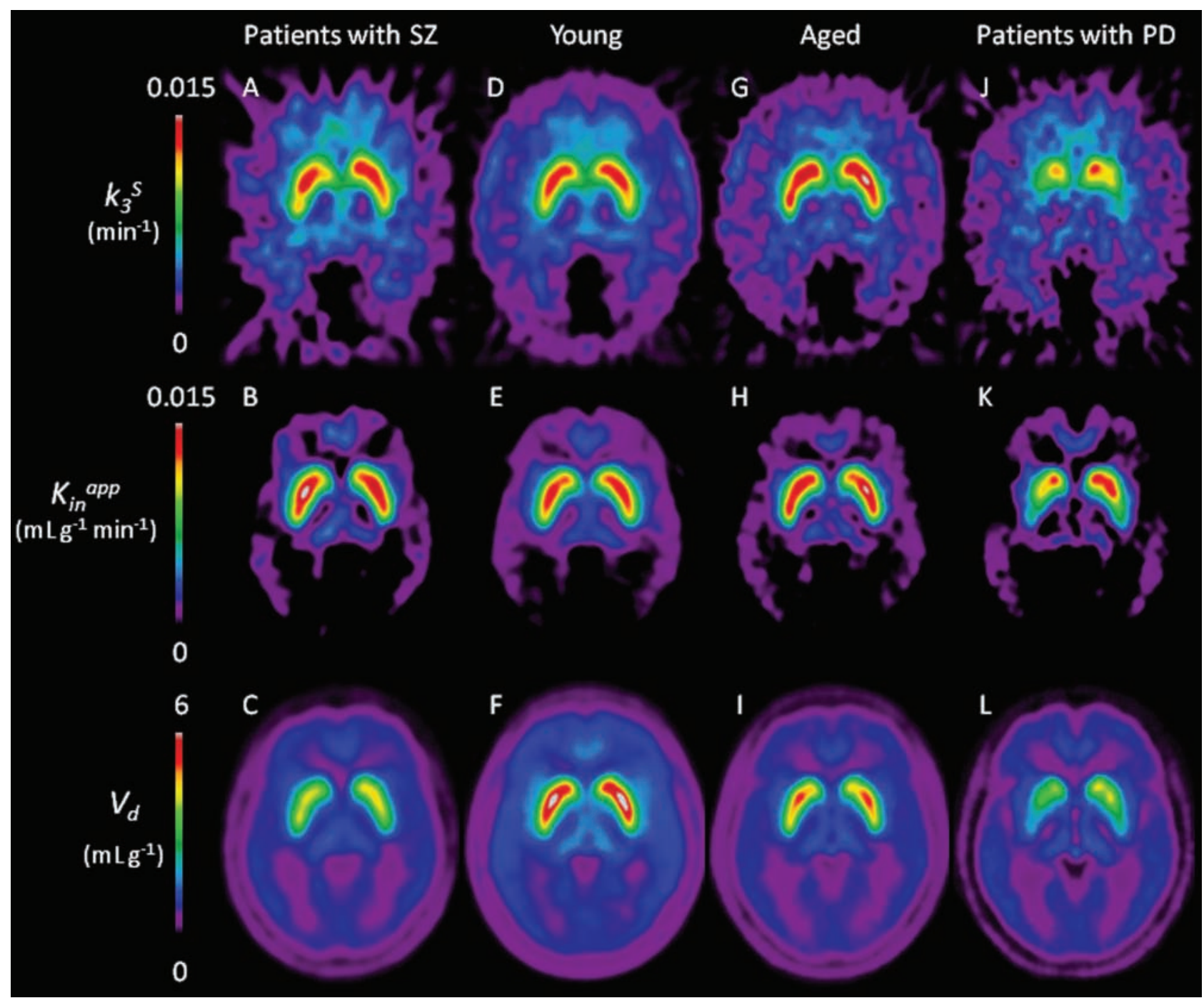

Figure 4. Mean parametric maps of 6-[ $\left.{ }^{[8} \mathrm{F}\right]$ fluoro-L-dopa (FDOPA) utilization and trapping in groups of patients with schizophrenia (SZ; $n=8)$, young healthy subjects $(n=14)$, aged healthy subjects $(n=14)$, and patients with Parkinson's disease (PD; $n=8)$. Maps show the FDOPA utilization relative to a reference tissue input $\left(k_{3}^{s}\right)$, the conventional linear graphical analysis of FDOPA influx $\left(K_{i n}{ }^{\text {app }}\right)$, and the steadystate distribution volume of FDOPA $\left(V_{d}\right)$.

\section{The Three Compartments for FDOPA Pharmacokinetic Modeling}

The objective of technically demanding compartmental modeling for FDOPA is to estimate the rate constant for the formation of $\left[{ }^{18} \mathrm{~F}\right]$ fluorodopamine in living brain, expressed as the AAADC enzyme activity rate constant $k_{3}^{D}\left(\mathrm{~min}^{-1}\right)$. As such, FDOPA is one of the very few PET tracers for measuring the activity of an enzyme in living brain. According to the conventions of compartmental analysis, the total radioactivity concentration in brain is distributed into three compartments: FDOPA in blood, FDOPA in the brain tissue (the precursor pool), and the metabolite compartment (trapped $\left[{ }^{18} \mathrm{~F}\right]$ fluorodopamine), neglecting, for the sake of clarity, the background of OMFD (Fig. 2A). The common carrier for large neutral amino acids facilitates the diffusion of plasma FDOPA to brain; this unidirectional blood-brain clearance $\left(K_{1}^{D} ; \mathrm{mL} \mathrm{g}^{-1} \mathrm{~min}^{-1}\right)$ is equal to the product of the extraction fraction of FDOPA multiplied by cerebral blood flow. The common carrier for large amino acids acts as a "revolving door," such that brain FDOPA is cleared back to circulation $\left(k_{2}{ }^{D} \mathrm{~min}^{-1}\right)$. The net effect is that FDOPA, OMFD, and the endogenous large neutral amino acid substrates are all equilibrated across the blood-brain barrier, a concept that inspired the constrained approach for compartmental analysis of FDOPA in the presence of OMFD (Gjedde and others 1991; Huang and others 1991). In this model, the number of free parameters describing the blood-brain 
partitioning of FDOPA and OMFD is reduced from 4 to 2 by the following assumptions: First, it is assumed that the blood-brain partitioning of FDOPA at equilibrium $\left(V_{e}^{D}=K_{1}{ }^{D} / k_{2}{ }^{D}\right)$ is identical to that of OMFD $\left(V_{e}^{M}\right.$ $\left.=K_{1}^{M} / k_{2}^{M}\right)$. Second, this partitioning is assumed to be homogeneous throughout the brain. Finally, the magnitude of the unidirectional clearance of OMFD to that of FDOPA $\left(q: K_{1}^{M} / K_{1}^{D}\right)$ is set at a fixed ratio, based upon early experiments $(q=1.5$; Cumming and Gjedde 1998). Although there remains some uncertainty about the true magnitude of $q$, the compartmental analysis is quite stable over a range of physiologically plausible $q$ values (Leger and others 1998).

\section{Conventional compartmental analysis using nonlinear least square optimization}

The compartmental analysis of FDOPA metabolism in brain requires the dual arterial FDOPA and OMFD inputs mentioned above. Using the constrained approach, the nonlinear least square fitting is first obtained for the TAC in a reference region where the magnitude of $k_{3}{ }^{D}$ is plausibly fixed at zero, thus yielding an estimate of the common partition volume FDOPA and OMFD, $V_{e}$, which has units $\mathrm{mL} \mathrm{g}^{-1}$. This estimate is then used as a constraint to reduce the number of parameters to be estimated in striatum to only two, namely $K_{1}{ }^{D}$ and $k_{3}{ }^{D}$. Typical TACs in cerebellum and putamen are presented in Figure 3; results of fitting can be seen in our earlier publication (Kumakura and others 2005, Fig. 2).

\section{The True Activity of AAADC in Living Brain}

Compartmental analysis of FDOPA-PET studies gives estimates of the relative activity of AAADC $\left(k_{3}{ }^{D}\right)$ generally close to $0.06 \mathrm{~min}^{-1}$ in striatum of healthy humans. According to Michaelis-Menten kinetics, the magnitude of $k_{3}{ }^{D}$ should equal $V_{m o x} / K_{m} V_{d}$ (Reith and others 1994), predicting a magnitude of $1 \mathrm{~min}^{-1}$ on the basis of AAADC activity measured in homogenates of monkey striatum (Yee and others 2000) or rat striatum (Cumming and others 1988). How to account for the 15-fold discrepancy between PET and enzymology results? Intrinsic factors in vivo might attenuate the AAADC activity with respect to FDOPA. On the other hand, typical estimates of $k_{3}{ }^{D}$ based on biochemical analysis of metabolites in extracts from rat striatum $\left(0.2 \mathrm{~min}^{-1}\right)$ are closer to the predicted rate constant. Furthermore, the relatively low spatial resolution of PET results in substantial degradation of the measured brain TACs. Correcting FDOPA scans for the so-called effects of partial volume suggests that the "true" magnitude of $k_{3}{ }^{D}$ in the striatum of normal humans is considerably higher than previously suspected (Rousset and others 2000), falling in the range of the biochemical estimates.

\section{Steady-State Methods for the Quantitation of FDOPA-PET Studies}

All of the methods described above assume that $\left[{ }^{18} \mathrm{~F}\right]$ fluorodopamine, once formed, is irreversibly trapped within synaptic vesicles. However, plots of the linear graphical analysis, and also compartmental modeling results (Fig. 3), suggest that striatal radioactivity concentrations eventually fall under the calculated or extrapolated curves. To correct for washout of trapped mass, an extended compartmental model must accommodate 1) the progressive catabolism of $\left[{ }^{18} \mathrm{~F}\right]$ fluorodopamine, and 2 ) the diffusion of acidic metabolites from brain. Adding the two kinetic parameters would entail an insupportable overspecification of the model. Therefore, these two processes have been lumped as a net washout rate constant $k_{\text {loss }}\left(\mathrm{min}^{-1}\right)$ (Huang and others 1991), in which $\left[{ }^{18} \mathrm{~F}\right]$ fluorodopamine and its acidic metabolites are considered a single diffusible pool. This becomes essentially true for FDOPA-PET recordings longer than 1 hour, when an equilibrium develops between the vesicular and diffusible pools (Deep and others 1997a, 1997b).

The extended compartmental analysis does not give stable estimates of $k_{\text {loss }}$ when FDOPA recordings lasting only 2 hours are available (Danielsen and others 1999). However, stable estimates of the magnitude of $k_{3}{ }^{D}$ corrected for loss of the $\left[{ }^{18} \mathrm{~F}\right]$ fluorodopamine metabolites $\left(k_{3}{ }^{D^{*}}\right)$ can be readily calculated in monkeys scanned for 4 hours (Cumming and others 2001), during which time the washout of metabolites becomes quite substantial. Indeed, the magnitude of $k_{3}{ }^{D}$ in monkey putamen is some $40 \%$ less than is $k_{3}^{D^{*}}$, indicating that the irreversible trapping model underestimates the AAADC activity because much of the $\left[{ }^{18} \mathrm{~F}\right]$ fluorodopamine formed in brain has already been lost during the first hour of the PET study.

\section{Relinearizing the Graphical Analysis}

The deviating graphical analysis of prolonged FDOPAPET recordings can be relinearized by addition of an exponential term representing $k_{\text {loss }}$ (Holden and others 1997; Cumming and others 2001; Sossi and others 2001). Using this approach, the effect of COMT inhibition on $k_{\text {loss }}$ has been investigated; treatment with a COMT inhibitor acting in the central nervous system, the magnitude of $k_{\text {loss }}$ declined by $40 \%$ in monkey striatum, whereas a peripherally acting COMT inhibitor was without effect on $k_{\text {loss }}$ (Holden and others 1997). This isolated finding suggests that brain COMT plays rather a greater role in the eventual catabolism of $\left[{ }^{18} \mathrm{~F}\right]$ fluorodopamine than has generally been appreciated, or may suggest a vulnerability of the model to altered FDOPA methylation in situ $\left(k_{5}{ }_{5}\right.$; Cumming and Gjedde, 1998).

The ratio of the net tracer clearance to brain $\left(K_{i n}{ }^{a p p}\right)$ to $k_{\text {loss }}$ has been called the effective distribution volume 
of FDOPA in brain (EDV; $\left.\mathrm{mL} \mathrm{g}^{-1}\right)$, corresponding to the steady-state FDOPA trapping capacity in brain (Sossi and others 2001). Whereas the magnitude of $K_{\text {in }}{ }^{a p p}$ had declined by only $27 \%$ in the putamen of patients with Parkinson's disease, the magnitude of EDV had declined by $65 \%$ (Sossi and others 2004). Thus, the steady-state analysis is a more sensitive indicator of nigrostriatal degeneration, but requires 4-hour-long recordings. Therefore, an alternate method has been developed to estimate steady-state FDOPA kinetics using recordings lasting a more tolerable 2 hours (Kumakura and others 2005, 2006). In this approach, the constrained compartmental model is first fitted to the reference tissue TAC, to calculate the separate FDOPA and OMFD TACs. Given that the OMFD concentration is nearly uniform in the brain, the OMFD TAC is then subtracted frame-byframe from the entire volume of the dynamic PET scan. This subtraction isolates the brain radioactivity due to FDOPA, $\left[{ }^{18} \mathrm{~F}\right]$ fluorodopamine, and the acid metabolites, while avoiding the oversubtraction of FDOPA when the entire tissue radioactivity (OMFD and FDOPA) is subtracted, as in the conventional graphical analysis. Using the "mathematically cleaned" FDOPA recordings, we then calculate in each region of interest the magnitudes of the intrinsic FDOPA clearance $(K)$ and $k_{\text {loss }}$. The several estimates of the magnitude of $k_{\text {loss }}$ (Table 2) predict a half-life for brain $\left[{ }^{18} \mathrm{~F}\right]$ fluorodopamine of approximately 2 hours in healthy striatum, similar to that seen in biochemical assays of dopamine turnover.

\section{Optimization Using Multilinear Solution for $k_{\text {loss }}$ and EDV}

Our first attempts to measure $k_{\text {loss }}$ and $E D V$ using mathematical subtraction of OMFD were based on nonlinear fitting of the resultant uptake curves (Kumakura and others 2005). However, our nonlinear methods involving cost-function optimization tended to fail in voxelwise parameter estimation. To address this problem, we developed a robust linear approach for FDOPA steady-state parametric mapping for the calculation of steady-state parameters in terms of the calculated FDOPA arterial input $\left(C_{p}(t)\right)$ and the total mass of the tracer in brain, $M(t)$. We expressed the model as a multilinear equation,

$$
\begin{aligned}
\int_{0}^{t} M(\tau) d \tau= & \left\{E D V+\left(V_{f}+V_{0}\right)\right\} \\
& \int_{0}^{t} C_{p}(\tau) d \tau-\frac{M(t)}{k_{\text {loss }}}+\frac{V_{f}+V_{0}}{k_{\text {loss }}} C_{p}(t)
\end{aligned}
$$

where the distribution volume of unmetabolized FDOPA in brain tissue $\left(V_{f}\right)$ approaches a constant, $K_{l} /$ $\left(k_{2}+k_{3}\right)$, at some 20 minutes after FDOPA injection, and given an effective plasma volume in brain $\left(V_{0}\right)$, which should be close to 5\% (Kumakura and others 2006). The regression process enables calculation of the magnitudes of the three coefficients (macroparameters) on the right hand side. Of these, the term $\{E D V$ $\left.+\left(V_{f}+V_{0}\right)\right\}$, equal to the total distribution volume $\left(V_{d}\right)$, is the most reliable and robust parameter, and is the optimal term for parametric mapping based on 2-hour FDOPA-PET recordings (Kumakura and others 2008). This newly formulated "inlet-and-outlet" model (Fig. 2C) representing "internal irreversible kinetics contained in the global reversible kinetics" is clearly distinct from the conventional PET kinetic models (i.e., FDG or receptor ligands). Our novel modeling approach, predicated upon precise subtraction of brain OMFD contamination, allows the estimation of dopamine storage capacity (expressed as $V_{d}$ ) even in regions of sparse dopamine innervation (Kumakura and others 2008; Kienast and others 2008).

\section{Multiple Fates for FDOPA in Brain and the Pharmacological Modulation of AAADC Activity}

DOPA in brain has several possible fates, such that the activity of AAADC determines the "branching ratio" for the DOPA pathway. It follows that altering AAADC activity must change the fraction of DOPA proceeding to dopamine synthesis, rather than disposal by other pathways. This prediction has been tested in a number of pharmacological challenge studies with $\left[{ }^{3} \mathrm{H}\right] \mathrm{DOPA}$ in living rats. Results of these studies have consistently suggested modulation of striatal AAADC activity via presynaptic autoreceptors (see, for example, Cumming and others 1995b).

Based on the results of $\left[{ }^{3} \mathrm{H}\right]$ DOPA studies mentioned above, autoreceptor modulation of AAADC activity has been tested in PET paradigms. Challenge with a typical antipsychotic medication acutely increased the FDOPA influx $\left(K_{i n}{ }^{a p p}\right)$ in the putamen of healthy volunteers (Vernaleken and others 2006), suggesting activation of dopamine synthesis after autoreceptor blockade. In another such study, treatment of volunteers with an atypical antipsychotic failed to increase the striatal influx of FMT (Mamo and others 2004). This discrepancy may be related to the uncertain metabolic fate of FMT, or it may simply be that FMT uptake is prone to a ceiling effect, if its trapping in healthy striatum is already so efficient that any further increase approaches the limit in influx imposed by the clearance across the blood-brain barrier $\left(K_{1}^{D}\right)$. In another FDOPA-PET study, subchronic treatment with haloperidol decreased the magnitude of $k_{3}{ }^{D}$ in patients with schizophrenia, consistent with down-regulation of dopamine synthesis (Grunder and others 2003). This latter finding was interpreted to reveal the onset of depolarization block, a putative mechanism for the 3-week delay in full clinical 
response to antipsychotic treatment: if so, this would be the only evidence for the occurrence of depolarization block in the human brain.

\section{Age-Related Changes Measured by FDOPA-PET}

Cell counting studies generally have shown a $7 \%$ to $10 \%$ decline in the number of dopamine neurons of the substantia nigra with each decade of human life. Despite this precipitous decline in cell number, the activity of AAADC from postmortem brain was only $27 \%$ reduced in the caudate nucleus of elderly human subjects and was unchanged in the putamen (Kish and others 1995). Thus, compensatory changes may occur in the aging substantia nigra such that AAADC activity is preserved. Indeed, the great preponderance of FDOPA-PET studies have shown preserved tracer uptake with normal aging (Cumming and Gjedde 1998; Fig. 4). Similarly, there was only a trend toward declining FDOPA $k_{3}{ }^{S}$ in aged monkeys (Doudet and others 2006). However, numerous model-based factors and biases may underlie the absent age-related changes in FDOPA kinetics. Using methods described above, we have found that the conventional calculation of $K_{\text {in }}{ }^{\text {app }}$ conceals an underlying decline with age in the magnitude of the inherent net blood-brain clearance. Parametric maps of FDOPA influx based upon a more physiologically valid subtraction of the OMFD curve (Kumakura and others 2005) revealed, in fact, a substantial decline with normal aging, which could not be detected in the corresponding $k_{3}^{s}$ and $K_{\text {in }}{ }^{a p p}$ maps. However, the net FDOPA influx reveals the dopamine synthesis capacity, assuming irreversible trapping of the tracer. The steady-state kinetic analysis described above revealed the occurrence of a substantial increase with age in the magnitude of $k_{\text {loss }}$, the washout rate for $\left[{ }^{18} \mathrm{~F}\right]$ fluorodopamine formed in striatum. Thus, dopamine synthesis was normal, but the retention of dopamine was impaired as a function of age. The index of vesicular storage $\left(V_{d}\right)$, including these two terms, declined by $10 \%$ with each decade of healthy aging (Kumakura and others 2008), predicting that healthy aging would proceed to a condition of parkinsonism for otherwise healthy centenarians (Fig. 4). The FDOPA $K_{\text {in }}{ }^{a p p}$ was greater in the caudate nucleus of women than in agematched men (Laakso and others 2002), a finding that may have bearing on the slightly greater incidence of Parkinson's disease in men.

\section{Acquired Parkinsonism and Idiopathic Parkinson's Disease}

The relationship between FDOPA utilization and survival of dopamine neurons is best documented with the MPTP model of acquired parkinsonism in experimental animals. Here, PET results can be compared with postmortem histological analysis. Impaired FDOPA uptake in striatum of MPTP-poisoned monkeys was associated with atrophy of the remaining dopamine neurons in the substantia nigra (Pate and others 1993). Stereological cell counting showed that 200,000 dopamine neurons in the substantia nigra of healthy baboons supported an FDOPA $k_{3}{ }^{S}$ of $0.007 \mathrm{~min}^{-1}$ in the striatum. In severely MPTP-poisoned baboons, there remained only 67,000 dopamine neurons, which imparted an FDOPA $k_{3}{ }^{S}$ of only $0.001 \mathrm{~min}^{-1}$ (Poyot and others 2001). In monkeys with less severe MPTPpoisoning, reduced FDOPA utilization correlated better with striatal dopamine concentration measured postmortem (Yee and others 2001), and with striatal activity of AAADC in vitro (Yee and others 2000), than with numerical loss of dopamine neurons. Relative preservation of FDOPA $k_{3}{ }^{S}$ as a function of the severity of idiopathic Parkinson's disease suggests the occurrence of compensatory up-regulation of AAADC in residual dopamine terminals (Lee and others 2000). Indeed, the "nonlinearity" of FDOPA utilization has been noted earlier (Barrio and others 1997).

FMT-PET followed by postmortem histology in MPTP-poisoned monkeys revealed general agreement between the pattern of reduced tracer influx and the topography of remaining dopamine neurons (Oiwa and others 2003). In a study of xenografting in pigs with MPTP-induced parkinsonism, some functional recovery and improved FDOPA utilization was obtained in association with the grafting of approximately 100,000 dopamine neurons surviving ectopically in the dopamine-depleted striatum (Dall and others 2002). In a group of five patients with neurodegenerative disease, cell counts in the substantial nigra correlated with results of earlier FDOPA-PET examinations (Snow and others 1993); this seems to be the only instance of follow-up histological examination in human FDOPA studies.

In patients with early hemiparkinsonism, the FDOPA utilization was more reduced in the striatum contralateral to the motor symptoms, suggesting a threshold for decompensation (Morrish and others 1995). The rate of progression of Parkinson's disease has been investigated in a number of longitudinal PET studies. Thus, the annual declines of FDOPA $k_{3}{ }^{s}$ were $4 \%$ in the caudate and $6 \%$ in the putamen (Hilker and others 2005), or 6\% in the caudate and $10 \%$ in the putamen of patients with Parkinson's disease, versus less than $1 \%$ in healthy aged subjects (Nurmi and others 2001). In the REAL-PET study, the magnitude of $k_{3}{ }^{s}$ in the putamen declined by 6.5\% per year in patients with Parkinson's disease treated with ropinerole, versus $10 \%$ per year in patients treated with DOPA (Whone and others 2003), which may reveal a neuroprotective effect of direct dopamine agonists.

The first reductions in FDOPA utilization of early Parkinson's disease are noted in the dorsal putamen; follow-up at 2 years later shows a further decline in the 
dorsal putamen, along with additional loss in other regions of the striatum (Bruck and others 2006; Ishiwata and others 2007). Even in advanced Parkinson's disease, the FDOPA influx was less impaired in the caudate nucleus $(-45 \%)$ than in the putamen $(-64 \%$; Broussolle and others 1999). Elevated FDOPA utilization in the frontal cortex has been described in PET studies of early Parkinson's disease (Bruck and others 2005; Rakshi and others 1999), more notably in women than in men (Kaasinen and others 2001b).

\section{Other Clinical FDOPA Studies}

Increased FDOPA $K_{i n}{ }^{a p p}$ in the caudate of unmedicated patients with schizophrenia was an early finding in the history of quantitative FDOPA studies (Reith and others 1994). This finding has since been replicated in several independent studies with FDOPA (Hietala and others 1999), with notably large increases present in the ventral striatum (McGowan and others 2004). In studies with $\beta$-[ $\left.{ }^{11} \mathrm{C}\right] \mathrm{DOPA}$, there was increased net influx throughout the striatum, and also the medial prefrontal cortex (Lindstrom and others 1999), a finding that was normalized after treatment with antipsychotic drugs (Gefvert and others 2003). In an fMRI study of schizophrenia, the increased FDOPA influx to the striatum correlated with reduced BOLD signal changes in the prefrontal cortex during performance of a cognitive task (Meyer-Lindenberg and others 2002), suggesting a link between abnormal physiology of associated cortical and subcortical structures. FDOPA influx was also increased in the striatum of first-degree relatives of patients with schizophrenia (Huttunen and others 2008), suggesting that an overactive dopamine system may be a risk factor or trait marker for developing psychosis. Steady-state kinetic analysis showed the expected increase in FDOPA utilization and an even greater increase in $\left[{ }^{18} \mathrm{~F}\right]$ fluorodopamine washout $\left(k_{\text {loss }}\right)$ in patients with schizophrenia (Kumakura and others 2007). The net effect of these two increases was a reduced FDOPA $V_{d}$, a circumstance we described as "poverty in the midst of plenty" (Fig. 4). In a single FDOPA study of untreated patients with nonpsychotic mania, influx was normal, but was reduced by treatment with a mood stabilizer (Yatham and others 2002).

The FDOPA $K_{\text {in }}{ }^{a p p}$ was $30 \%$ greater in the caudate nucleus of smokers than in nonsmoking control subjects (Salokangas and others 2000). It remains uncertain if this reflects a pharmacological action of tobacco smoke, or an underlying personality trait associated predisposing for smoking. However, acute treatment with nicotine increased the utilization of $\beta-\left[{ }^{11} \mathrm{C}\right] \mathrm{DOPA}$ in the striatum of awake monkeys (Tsukada and others 2005). Thus, it is interesting that the magnitude of FDOPA $K_{i n}{ }^{a p p}$ was entirely normal in the striatum of alcoholics, but nonetheless correlated inversely with individual scores for craving, a predictor for relapse (Heinz and others 2005). It is as if the pathological trait expresses itself through the (essentially normal) dopamine system at hand. FDOPA-PET could be used to identify a subset of alcoholic patients potentially benefiting from treatment with DOPA or direct dopamine agonists.

\section{Personality and Cognition}

Psychological test batteries can score distinct trait and propensities, and their relationship results of PET studies. The Tridimensional Personality Questionnaire of Cloninger provides scores on three distinct axes, known as reward dependence, novelty seeking, and harm avoidance, to which is sometimes added the additional dimension of persistence. In an FDOPA-PET study of patients with Parkinson's disease, FDOPA uptake in the caudate correlated positively with the novelty seeking (Menza and others 1995) and harm-avoidance scores (Kaasinen and others 2001a). These results may support the usual clinical observation that patients with Parkinson's disease tend to be withdrawn and lacking in adventurousness. However, there was no relationship between FDOPA influx and harm avoidance in healthy elderly control subjects (Kaasinen and others 2002). High scores in ratings of anxiety and aggressiveness, which was assessed with another self-report questionnaire, the Karolinska Scales of Personality, correlated with low influx of FDOPA in the caudate nucleus of normal young subjects (Laakso and others 2003).

In an FDOPA study employing principle component analysis, impaired FDOPA utilization segregated with motor symptoms, but not cognitive function and mood of Parkinson's patients without diagnosis of major depression (Broussolle and others 1999). This would seem to exclude important contributions of nigrostriatal degeneration per se to declining cognitive function and mood in patients with Parkinson's disease. However, others have reported that reduced FDOPA influx specifically to caudate predicted poor performance of the Stroop interference task, a test of executive function of the frontal lobes (Rinne and others 2000). In a subsequent FDOPA study of cognition in patients with Parkinson's disease, there was a very high correlation between impaired FDOPA uptake in the caudate nucleus and putamen with scores in a item known as "concentration difficulties" (Koerts and others 2007). However, this finding need not necessarily indicate a causal link, inasmuch as the decline in striatum FDOPA metabolism might be a surrogate marker for other pathologies impairing cognitive function.

In healthy subjects, the score in the performance of the Stroop test correlated with FDOPA $K_{\text {in }}{ }^{a p p}$ throughout the striatum of a group of healthy volunteers (Vernaleken and others 2007), a finding that was corroborated in an FMT-PET study showing a positive 
correlation between striatal tracer uptake and digit span of healthy subjects (Cools and others 2008). These findings stand in contrast to the reported relationship between prefrontal BOLD signal and FDOPA influx in patients with schizophrenia, cited above, in which impaired prefrontal activity predicted especially elevated FDOPA influx. In another dual-modality imaging study of normal subjects, the magnitude of activation of the fMRI BOLD signal evoked in frontal cortex by emotionally positive visual stimuli correlated with FDOPA $K_{i n}{ }^{a p p}$ in the ventral striatum (Siessmeier and others 2006). More recently, the "inlet-outlet" model has been used to investigate the relationship between normal cognition and FDOPA metabolism (Vernaleken and others 2008). Within the healthy group, some subjects were characterized by a volatile dopamine system, with low FDOPA influx and rapid turnover of $\left[{ }^{18} \mathrm{~F}\right]$ fluorodopamine, whereas others had a seemingly indolent system, with high FDOPA influx and low turnover. Only the former subgroup experienced improved cognition under treatment with haloperidol, suggesting that individual differences in the dynamic range of the responsiveness of dopamine systems may be a factor related to "cognitive style."

This last observation introduces the concept of FDOPA "parameter space" defined by the twin axes of inherent to the steady-state model. Here, the capacity to synthesize dopamine, as revealed by the net influx of tracer to brain $\left(K\right.$ or $\left.K_{i n}{ }^{a p p}\right)$, is functionally distinct from the rate of dopamine turnover, which is related to $k_{\text {loss }}$ Normal individuals can occupy a certain domain of these two parameters, which changes as a function of normal aging. To some extent, one's cognitive performance, motor behavior, and vulnerability to disease may be influenced by the position in this parameter space, while still remaining within the normal limits for a given age group. However, patients with diseases such as schizophrenia or Parkinson's disease clearly occupy distinct domains of FDOPA parameter space, as depicted in Figure 5.

In conclusion, the methodologically convenient estimates of FDOPA net influx are sensitive and useful indicators of several neuropsychiatric disorders. However, the more sophisticated steady-state analysis can reveal deeper insights into the life of the dopamine neurons, and can reveal abnormalities not evident in the simple measures of influx, which assume irreversible trapping of $\left[{ }^{18} \mathrm{~F}\right]$ fluorodopamine formed in living striatum. As discussed above, FDOPA-PET has been available for more than 25 years. However, the refinement of kinetic modeling has been a continuous process, leading to ever new insights about brain dopamine.

\section{Acknowledgment}

This work emerged from a collaboration with Professor Albert Gjedde and Dr. Erik Danielsen of the Aarhus

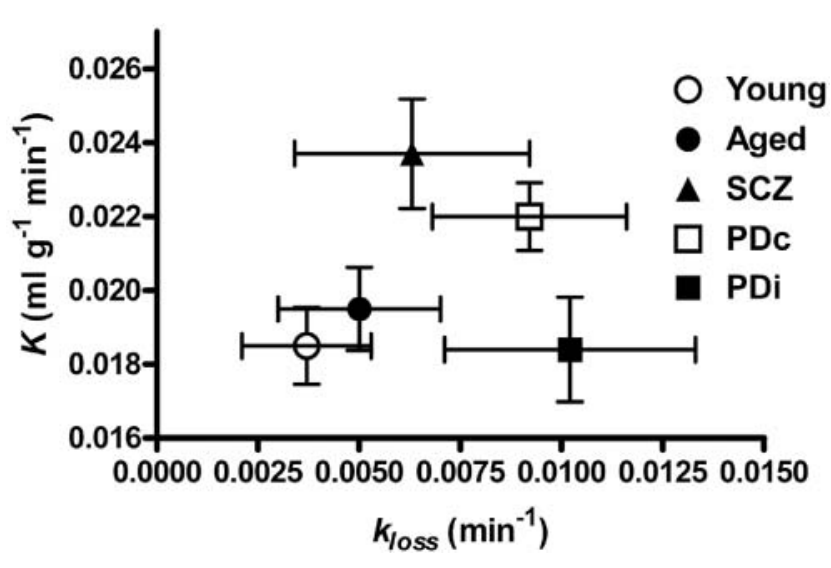

Figure 5. Position in 6-[18F]fluoro-L-dopa parameter space, defined by $K$ and $k_{\text {loss }}$, of groups of patients with schizophrenia (SCZ; $n=8)$, young healthy subjects $(n=14)$, aged healthy subjects $(n=14)$, and patients with Parkinson's disease (PD; $n=8)$, presented along with the standard deviation. In the case of PD, results are depicted contralateral (PDc) and ipsilateral (PDi) to the most affected hemisphere. These groups are exactly the same populations as depicted in Figure 4.

University PET Center, Professor Andreas Heinz and Dr. Thorsten Kienast of the Department of Psychiatry of the Charite Hospital in Berlin, Professor Peter Bartenstein of the Department of Nuclear Medicine, LudwigMaximilians University of Munich, and Professors Gerhard Gruender and Ingo Vernaleken of the Department of Psychiatry, Aachen University Hospital.

\section{References}

Barrio JR, Huang SC, Phelps ME. 1997. Biological imaging and the molecular basis of dopaminergic diseases. Biochem Pharmacol 54:341-8.

Boyes BE, Cumming P, Martin WR, McGeer EG. 1986. Determination of plasma [18F]-6-fluorodopa during positron emission tomography: elimination and metabolism in carbidopa treated subjects. Life Sci 39:2243-52.

Broussolle E, Dentresangle C, Landais P, Garcia-Larrea L, Pollak P, Croisile B, and others. 1999. The relation of putamen and caudate nucleus 18F-Dopa uptake to motor and cognitive performances in Parkinson's disease. J Neurol Sci 166:141-51.

Brown WD, DeJesus OT, Pyzalski RW, Malischke L, Roberts AD, Shelton SE, and others. 1999. Localization of trapping of 6-[(18)F]fluoro-L-m-tyrosine, an aromatic L-amino acid decarboxylase tracer for PET. Synapse 34:111-23.

Bruck A, Aalto S, Nurmi E, Bergman J, Rinne JO. 2005. Cortical 6-[18F]fluoro-L-dopa uptake and frontal cognitive functions in early Parkinson's disease. Neurobiol Aging 26:891-8.

Bruck A, Aalto S, Nurmi E, Vahlberg T, Bergman J, Rinne JO. 2006. Striatal subregional 6-[18F]fluoro-L-dopa uptake in early Parkinson's disease: a two-year follow-up study. Mov Disord 21:958-63. 
Cools R, Gibbs SE, Miyakawa A, Jagust W, D’Esposito M. 2008. Working memory capacity predicts dopamine synthesis capacity in the human striatum. J Neurosci 28:1208-12.

Cumming P, Ase A, Diksic M, Harrison J, Jolly D, Kuwabara H, and others. 1995a. Metabolism and blood-brain clearance of L-3,4-dihydroxy-[3H]phenylalanine ([3H]DOPA) and 6-[18F]fluoro-L-DOPA in the rat. Biochem Pharmacol 50:943-6.

Cumming P, Boyes BE, Martin WR, Adam M, Grierson J, Ruth T, and others. 1987. The metabolism of [18F]6fluoro-L-3,4-dihydroxyphenylalanine in the hooded rat. J Neurochem 48:601-8.

Cumming P, Gjedde A. 1998. Compartmental analysis of dopa decarboxylation in living brain from dynamic positron emission tomograms. Synapse 29:37-61.

Cumming P, Hausser M, Martin WR, Grierson J, Adam MJ, Ruth TJ, and others. 1988. Kinetics of in vitro decarboxylation and the in vivo metabolism of $2-18 \mathrm{~F}$ - and 6-18F-fluorodopa in the hooded rat. Biochem Pharmacol $37: 247-50$.

Cumming P, Kuwabara H, Ase A, Gjedde A. 1995b. Regulation of DOPA decarboxylase activity in brain of living rat. J Neurochem 65:1381-90.

Cumming P, Leger GC, Kuwabara H, Gjedde A. 1993. Pharmacokinetics of plasma 6-[18F]fluoro-L-3,4-dihydroxyphenylalanine ([18F]Fdopa) in humans. J Cereb Blood Flow Metab 13:668-75.

Cumming P, Munk OL, Doudet D. 2001. Loss of metabolites from monkey striatum during PET with FDOPA. Synapse $41: 212-8$.

Dall AM, Danielsen EH, Sorensen JC, Andersen F, Moller A, Zimmer J, and others. 2002. Quantitative [18F]fluorodopa/ PET and histology of fetal mesencephalic dopaminergic grafts to the striatum of MPTP-poisoned minipigs. Cell Transplant 11:733-46.

Danielsen EH, Smith DF, Gee AD, Venkatachalam TK, Hansen SB, Hermansen F, and others. 1999. Cerebral 6-[(18)F]fluoro-L-DOPA (FDOPA) metabolism in pig studied by positron emission tomography. Synapse 33:247-58.

Deep P, Gjedde A, Cumming P. 1997a. On the accuracy of an [18F]FDOPA compartmental model: evidence for vesicular storage of $[18 \mathrm{~F}]$ fluorodopamine in vivo. J Neurosci Methods 76:157-65.

Deep P, Kuwabara H, Gjedde A, Cumming P. 1997b. The kinetic behaviour of [3H]DOPA in living rat brain investigated by compartmental modelling of static autoradiograms. J Neurosci Methods 78:157-68.

Doudet DJ, Chan GL, Jivan S, DeJesus OT, McGeer EG, English C, and others. 1999. Evaluation of dopaminergic presynaptic integrity: 6-[18F]fluoro-L-dopa versus 6-[18F] fluoro-L-m-tyrosine. J Cereb Blood Flow Metab 19:278-87.

Doudet DJ, Rosa-Neto P, Munk OL, Ruth TJ, Jivan S, Cumming P. 2006. Effect of age on markers for monoaminergic neurons of normal and MPTP-lesioned rhesus monkeys: a multi-tracer PET study. Neuroimage 30: $26-35$.

Endres CJ, Swaminathan S, DeJesus OT, Sievert M, Ruoho AE, Murali D, and others. 1997. Affinities of dopamine analogs for monoamine granular and plasma membrane transporters: implications for PET dopamine studies. Life Sci 60:2399-406.
Firnau G, Sood S, Chirakal R, Nahmias C, Garnett ES. 1987. Cerebral metabolism of 6-[18F]fluoro-L-3,4-dihydroxyphenylalanine in the primate. J Neurochem 48:1077-82.

Garnett ES, Firnau G, Nahmias C. 1983. Dopamine visualized in the basal ganglia of living man. Nature 305:137-138.

Gefvert O, Lindstrom LH, Waters N, Waters S, Carlsson A, Tedroff J. 2003. Different corticostriatal patterns of L-DOPA utilization in patients with untreated schizophrenia and patients treated with classical antipsychotics or clozapine. Scand J Psychol 44:289-92.

Gjedde A. 1982. Calculation of cerebral glucose phosphorylation from brain uptake of glucose analogs in vivo: a reexamination. Brain Res 257:237-74.

Gjedde A, Reith J, Dyve S, Leger G, Guttman M, Diksic M, and others. 1991. Dopa decarboxylase activity of the living human brain. Proc Natl Acad Sci U S A 88:2721-5.

Grunder G, Vernaleken I, Muller MJ, Davids E, Heydari N, Buchholz HG, and others. 2003. Subchronic haloperidol downregulates dopamine synthesis capacity in the brain of schizophrenic patients in vivo. Neuropsychopharmacology 28:787-94.

Hartvig P, Agren H, Reibring L, Tedroff J, Bjurling P, Kihlberg T, and others. 1991. Brain kinetics of L-[beta$11 \mathrm{C}]$ dopa in humans studied by positron emission tomography. J Neural Transm Gen Sect 86:25-41.

Heinz A, Siessmeier T, Wrase J, Buchholz HG, Grunder G, Kumakura Y, and others. 2005. Correlation of alcohol craving with striatal dopamine synthesis capacity and D2/3 receptor availability: a combined [18F]DOPA and [18F]DMFP PET study in detoxified alcoholic patients. Am J Psychiatry 162:1515-20.

Hietala J, Syvalahti E, Vilkman H, Vuorio K, Rakkolainen V, Bergman J, and others. 1999. Depressive symptoms and presynaptic dopamine function in neuroleptic-naive schizophrenia. Schizophr Res 35:41-50.

Hilker R, Schweitzer K, Coburger S, Ghaemi M, Weisenbach S, Jacobs AH, and others. 2005. Nonlinear progression of Parkinson disease as determined by serial positron emission tomographic imaging of striatal fluorodopa F 18 activity. Arch Neurol 62:378-82.

Holden JE, Doudet D, Endres CJ, Chan GL, Morrison KS, Vingerhoets FJ, and others. 1997. Graphical analysis of 6-fluoro-L-dopa trapping: effect of inhibition of catecholO-methyltransferase. J Nucl Med 38:1568-74.

Hoshi H, Kuwabara H, Leger G, Cumming P, Guttman M, Gjedde A. 1993. 6-[18F]Fluoro-L-dopa metabolism in living human brain: a comparison of six analytical methods. J Cereb Blood Flow Metab 13:57-69.

Huang SC, Yu DC, Barrio JR, Grafton S, Melega WP, Hoffman JM, and others. 1991. Kinetics and modeling of L-6-[18F]fluoro-dopa in human positron emission tomographic studies. J Cereb Blood Flow Metab 11:898-913.

Huttunen J, Heinimaa M, Svirskis T, Nyman M, Kajander J, Forsback S, and others. 2008. Striatal dopamine synthesis in first-degree relatives of patients with schizophrenia. Biol Psychiatry 63:114-7.

Ishiwata K, Kawamura K, Yanai K, Hendrikse NH. 2007. In vivo evaluation of $\mathrm{P}$-glycoprotein modulation of 8 PET radioligands used clinically. J Nucl Med 48:81-7.

Jordan S, Bankiewicz KS, Eberling JL, VanBrocklin HF, O’Neil JP, Jagust WJ. 1998. An in vivo microdialysis study of 
striatal 6-[18F]fluoro-L-m-tyrosine metabolism. Neurochem Res 23:513-7.

Kaasinen V, Nurmi E, Bergman J, Eskola O, Solin O, Sonninen P, and others. 2001a. Personality traits and brain dopaminergic function in Parkinson's disease. Proc Natl Acad Sci U S A 98:13272-7.

Kaasinen V, Nurmi E, Bergman J, Solin O, Kurki T, Rinne JO. 2002. Personality traits and striatal 6-[18F]fluoro-L-dopa uptake in healthy elderly subjects. Neurosci Lett 332:61-4.

Kaasinen V, Nurmi E, Bruck A, Eskola O, Bergman J, Solin O, and others. 2001b. Increased frontal [(18)F]fluorodopa uptake in early Parkinson's disease: sex differences in the prefrontal cortex. Brain 124:1125-30.

Kienast T, Hariri AR, Schlagenhauf F, Wrase J, Sterzer P, Buchholz HG, and others. 2008. Dopamine in amygdala gates limbic processing of aversive stimuli in humans. Nat Neurosci 11:1381-2.

Kish SJ, Zhong XH, Hornykiewicz O, Haycock JW. 1995. Striatal 3,4-dihydroxyphenylalanine decarboxylase in aging: disparity between postmortem and positron emission tomography studies? Ann Neurol 38:260-4.

Koerts J, Leenders KL, Koning M, Portman AT, van Beilen M. 2007. Striatal dopaminergic activity (FDOPA-PET) associated with cognitive items of a depression scale (MADRS) in Parkinson's disease. Eur J Neurosci 25:3132-6.

Kumakura Y, Cumming P, Vernaleken I, Buchholz HG, Siessmeier T, Heinz A, and others. 2007. Elevated [18F] fluorodopamine turnover in brain of patients with schizophrenia: an [18F]fluorodopa/positron emission tomography study. J Neurosci 27:8080-7.

Kumakura Y, Gjedde A, Danielsen EH, Christensen S, Cumming P. 2006. Dopamine storage capacity in caudate and putamen of patients with early Parkinson's disease: correlation with asymmetry of motor symptoms. J Cereb Blood Flow Metab 26:358-70.

Kumakura Y, Vernaleken I, Buchholz HG, Borghammer P, Danielsen E, Grunder G, and others. 2008. Age-dependent decline of steady state dopamine storage capacity of human brain: an FDOPA PET study. Neurobiol Aging 2008. Jun 7 [Epub ahead of print].

Kumakura Y, Vernaleken I, Grunder G, Bartenstein P, Gjedde A, Cumming P. 2005. PET studies of net bloodbrain clearance of FDOPA to human brain: age-dependent decline of [18F]fluorodopamine storage capacity. J Cereb Blood Flow Metab 25:807-19.

Laakso A, Vilkman H, Bergman J, Haaparanta M, Solin O, Syvalahti E, and others. 2002. Sex differences in striatal presynaptic dopamine synthesis capacity in healthy subjects. Biol Psychiatry 52:759-63.

Laakso A, Wallius E, Kajander J, Bergman J, Eskola O, Solin O, and others. 2003. Personality traits and striatal dopamine synthesis capacity in healthy subjects. Am J Psychiatry 160:904-10.

Lee CS, Samii A, Sossi V, Ruth TJ, Schulzer M, Holden JE, and others. 2000. In vivo positron emission tomographic evidence for compensatory changes in presynaptic dopaminergic nerve terminals in Parkinson's disease. Ann Neurol 47:493-503.

Leger G, Gjedde A, Kuwabara H, Guttman M, Cumming P. 1998. Effect of catechol-O-methyltransferase inhibition on brain uptake of $[18 \mathrm{~F}]$ fluorodopa: implications for compartmental modelling and clinical usefulness. Synapse 30:351-61.

Lindstrom LH, Gefvert O, Hagberg G, Lundberg T, Bergstrom M, Hartvig P, and others. 1999. Increased dopamine synthesis rate in medial prefrontal cortex and striatum in schizophrenia indicated by L-(beta-11C) DOPA and PET. Biol Psychiatry 46:681-8.

Mamo D, Remington G, Nobrega J, Hussey D, Chirakal R, Wilson AA, and others. 2004. Effect of acute antipsychotic administration on dopamine synthesis in rodents and human subjects using 6-[18F]-L-m-tyrosine. Synapse 52:153-62.

Martin WR, Palmer MR, Patlak CS, Calne DB. 1989. Nigrostriatal function in humans studied with positron emission tomography. Ann Neurol 26:535-42.

McGowan S, Lawrence AD, Sales T, Quested D, Grasby P. 2004. Presynaptic dopaminergic dysfunction in schizophrenia: a positron emission tomographic [18F]fluorodopa study. Arch Gen Psychiatry 61:134-42.

Menza MA, Mark MH, Burn DJ, Brooks DJ. 1995. Personality correlates of $[18 \mathrm{~F}]$ dopa striatal uptake: results of positron-emission tomography in Parkinson's disease. J Neuropsychiatry Clin Neurosci 7:176-9.

Meyer-Lindenberg A, Miletich RS, Kohn PD, Esposito G, Carson RE, Quarantelli M, and others. 2002. Reduced prefrontal activity predicts exaggerated striatal dopaminergic function in schizophrenia. Nat Neurosci 5:267-71.

Morrish PK, Sawle GV, Brooks DJ. 1995. Clinical and [18F] dopa PET findings in early Parkinson's disease. J Neurol Neurosurg Psychiatry 59:597-600.

Nurmi E, Ruottinen HM, Bergman J, Haaparanta M, Solin O, Sonninen P, and others. 2001. Rate of progression in Parkinson's disease: a 6-[18F]fluoro-L-dopa PET study. Mov Disord 16:608-15.

Oiwa Y, Eberling JL, Nagy D, Pivirotto P, Emborg ME, Bankiewicz KS. 2003. Overlesioned hemiparkinsonian non human primate model: correlation between clinical, neurochemical and histochemical changes. Front Biosci 8:a155-66.

Pate BD, Kawamata T, Yamada T, McGeer EG, Hewitt KA, Snow BJ, and others. 1993. Correlation of striatal fluorodopa uptake in the MPTP monkey with dopaminergic indices. Ann Neurol 34:331-8.

Patlak CS, Blasberg RG. 1985. Graphical evaluation of bloodto-brain transfer constants from multiple-time uptake data. Generalizations. J Cereb Blood Flow Metab 5: 584-90.

Patlak CS, Blasberg RG, Fenstermacher JD. 1983. Graphical evaluation of blood-to-brain transfer constants from multipletime uptake data. J Cereb Blood Flow Metab 3:1-7.

Phelps ME, Huang SC, Hoffman EJ, Selin C, Sokoloff L, Kuhl DE. 1979. Tomographic measurement of local cerebral glucose metabolic rate in humans with (F-18)2-fluoro2-deoxy-D-glucose: validation of method. Ann Neurol 6:371-88.

Poyot T, Conde F, Gregoire MC, Frouin V, Coulon C, Fuseau C, and others. 2001. Anatomic and biochemical correlates of the dopamine transporter ligand 11C-PE2I in normal and parkinsonian primates: comparison with 6-[18F]fluoro-L-dopa. J Cereb Blood Flow Metab 21:782-92.

Rakshi JS, Uema T, Ito K, Bailey DL, Morrish PK, Ashburner J, and others. 1999. Frontal, midbrain and 
striatal dopaminergic function in early and advanced Parkinson's disease A 3D [(18)F]dopa-PET study. Brain 122. (Pt 9): 1637-50.

Reith J, Benkelfat C, Sherwin A, Yasuhara Y, Kuwabara H, Andermann F, and others. 1994. Elevated dopa decarboxylase activity in living brain of patients with psychosis. Proc Natl Acad Sci U S A 91:11651-4.

Rinne JO, Portin R, Ruottinen H, Nurmi E, Bergman J, Haaparanta M, and others. 2000. Cognitive impairment and the brain dopaminergic system in Parkinson disease: [18F]fluorodopa positron emission tomographic study. Arch Neurol 57:470-5.

Rousset OG, Deep P, Kuwabara H, Evans AC, Gjedde AH, Cumming P. 2000. Effect of partial volume correction on estimates of the influx and cerebral metabolism of 6-[(18) F]fluoro-L-dopa studied with PET in normal control and Parkinson's disease subjects. Synapse 37:81-9.

Salokangas RK, Vilkman H, Ilonen T, Taiminen T, Bergman J, Haaparanta M, and others. 2000. High levels of dopamine activity in the basal ganglia of cigarette smokers. Am J Psychiatry 157:632-4.

Siessmeier T, Kienast T, Wrase J, Larsen JL, Braus DF, Smolka MN, and others. 2006. Net influx of plasma 6-[18F]fluoro-L-DOPA (FDOPA) to the ventral striatum correlates with prefrontal processing of affective stimuli. Eur J Neurosci 24:305-13.

Snow BJ, Tooyama I, McGeer EG, Yamada T, Calne DB, Takahashi H, and others. 1993. Human positron emission tomographic [18F]fluorodopa studies correlate with dopamine cell counts and levels. Ann Neurol 34:324-30.

Sossi V, de la Fuente-Fernandez R, Holden JE, Schulzer M, Ruth TJ, Stoessl J. 2004. Changes of dopamine turnover in the progression of Parkinson's disease as measured by positron emission tomography: their relation to disease-compensatory mechanisms. J Cereb Blood Flow Metab 24:869-76.

Sossi V, Doudet DJ, Holden JE. 2001. A reversible tracer analysis approach to the study of effective dopamine turnover. J Cereb Blood Flow Metab 21:469-76.

Torstenson R, Tedroff J, Hartvig P, Fasth KJ, Langstrom B. 1999. A comparison of 11C-labeled L-DOPA and L-fluorodopa as positron emission tomography tracers for the presynaptic dopaminergic system. J Cereb Blood Flow Metab 19:1142-9.

Tsukada H, Miyasato K, Harada N, Nishiyama S, Fukumoto D, Kakiuchi T. 2005. Nicotine modulates dopamine synthesis rate as determined by L-[beta-11C]DOPA: PET studies compared with $[11 \mathrm{C}]$ raclopride binding in the conscious monkey brain. Synapse 57:120-2.

Vernaleken I, Buchholz HG, Kumakura Y, Siessmeier T, Stoeter P, Bartenstein P, and others. 2007. 'Prefrontal' cognitive performance of healthy subjects positively correlates with cerebral FDOPA influx: an exploratory [18F]fluoro-L-DOPA-PET investigation. Hum Brain Mapp 28:931-9.

Vernaleken I, Kumakura Y, Buchholz HG, Siessmeier T, Hilgers RD, Bartenstein P, and others. 2008. Baseline [18F]-FDOPA kinetics are predictive of haloperidolinduced changes in dopamine turnover and cognitive performance: a positron emission tomography study in healthy subjects. Neuroimage 40:1222-31.

Vernaleken I, Kumakura Y, Cumming P, Buchholz HG, Siessmeier T, Stoeter P, and others. 2006. Modulation of [18F]fluorodopa (FDOPA) kinetics in the brain of healthy volunteers after acute haloperidol challenge. Neuroimage 30:1332-9.

Whone AL, Watts RL, Stoessl AJ, Davis M, Reske S, Nahmias C, and others. 2003. Slower progression of Parkinson's disease with ropinirole versus levodopa: the REAL-PET study. Ann Neurol 54:93-101.

Yatham LN, Liddle PF, Shiah IS, Lam RW, Ngan E, Scarrow G, and others. 2002. PET study of [(18)F]6-fluoro-L-dopa uptake in neuroleptic- and mood-stabilizer-naive firstepisode nonpsychotic mania: effects of treatment with divalproex sodium. Am J Psychiatry 159:768-74.

Yee RE, Huang SC, Stout DB, Irwin I, Shoghi-Jadid K, Togaski DM, and others. 2000. Nigrostriatal reduction of aromatic L-amino acid decarboxylase activity in MPTPtreated squirrel monkeys: in vivo and in vitro investigations. J Neurochem 74:1147-57.

Yee RE, Irwin I, Milonas C, Stout DB, Huang SC, ShoghiJadid K, and others. 2001. Novel observations with FDOPAPET imaging after early nigrostriatal damage. Mov Disord 16:838-48.

For reprints and permissions queries, please visit SAGE's Web site at http://www.sagepub.com/journals Permissions.nav. 